\title{
PENGGUNAAN MEDIA FLASHCARD UNTUK MEMPERMUDAH \\ PENGUASAAN KOSAKATA BAHASA INGGRIS
}

\author{
UMMU JAUHARIN FARDA \\ Dosen FAI Unwahas Semarang \\ jaufaummu@yahoo.co.id
}

\begin{abstract}
Abstrak
Media flashcard dapat meningkatkan penguasaan kosakata siswa kelas IV pada mata pelajaran Bahasa Inggris dalam pokok bahasan Fruits And Vegetables. Dapat dibuktikan dengan hasil evaluasi nilai rata-rata 85 dan hasil ketuntasan klasikal sebesar $86 \%$. Metode penelitian yang digunakan adalah Penelitian Tindakan Kelas menggunakan media flashcard. Model penelitian meliputi beberapa tahap, yaitu Perencanaan (Planning), Implementasi Tindakan dan Pengamatan (Acting and Observe) dan Refleksi (Reflecting). Proses penelitian dilaksanakan sebanyak dua siklus yang terdiri atas dua kali pertemuan. hasil analisis data menyatakan bahwa, ada peningkatan yang signifikan pada nilai tes tiap siklus. Pada siklus I, siswa yang mendapat nilai lebih dari 75 sebanyak 23 (66\%) siswa dengan nilai rata-rata yang dicapai 73. Pada siklus II siswa yang mendapat nilai lebih dari 75 sebanyak30 (86\%) siswa dengan nilai rata-rata 85.
\end{abstract}

Kata kunci: PTK; Media Flashcard; Kosakata Bahasa Inggris

\section{Abstack}

Flashcard can increase the mastery of vocabulary for fourth grade primary school in English subject for theme Fruits and Vegetables. It proved by the result of average score evaluation is 85 and the percentage of whole exhaustiveness is $86 \%$. The method used in this Action Research is flashcard. Research Model covering some steps, they are Planning, Acting and 
Observe, and Reflecting. Research Process done in two cycles which consist of two meetings. Based on the analysis, there are significanse increase on test score in every cycle. In cycle 1, there are 26 (66\%) students who get score more than 75 with 73 in its average. In cycle 2, there are 30 (86\%) students who get score more than 75 with 85 in its average.

Keywords: Action Research, flashcard, English Vocabulary

\section{A. PENDAHULUAN}

Bahasa merupakan sarana yang sangat penting dalam kehidupan anak, karena dengan berbahasa anak dapat berkomunikasi dengan orang lain. ${ }^{1}$ Belajar bahasa tidak akan terlepas dari belajar kosakata, penguasaan kosakata merupakan hal terpenting dalam keterampilan berbahasa, tanpa penguasaan kosakata yang memadai, maka tujuan pembelajaran bahasa tidak akan tercapai, karena semakin banyak kosakata yang dimiliki seseorang, semakin terampil pula ia berbahasa. Penguasaan kosakata merupakan salah satu syarat utama yang menentukan keberhasilan seseorang untuk terampil berbahasa, semakin kaya kosakata seseorang semakin besar kemungkinan seseorang untuk terampil berbahasa dan semakin mudah pula ia menyampaikan dan menerima informasi baik secara lisan, tulisan, maupun menggunakan tanda-tanda dan isyarat.

1 Elizabeth B Hurlock, Psikologi Perkembangan, (Jakarta: Erlangga, 1980), hlm. 113. 
Mengingat ke depan persaingan yang dihadapi dengan bangsa lain maka tamatan suatu sekolah selain harus mempunyai kompetensi produktif juga harus mempunyai kompetensi Bahasa Inggris, karena Bahasa Inggris merupakan bahasa pengantar yang dipakai secara internasional dan untuk bisa berkomunikasi secara baik harus menguasai kosakata yang memadai pula. Peningkatan kosakata dapat dilakukan dengan berbagai macam cara melalui membaca, mendengarkan dan menonton. Peningkatan kosakata atau penguasaan kosakata tesebut lebih banyak dilakukan di dunia pendidikan.

Umumnya peningkatan kosakata di lembaga pendidikan anak dilakukan dengan menciptakan situasi yang memberikan kesempatan pada anak untuk mengembangkan kemampuan bahasanya. Kesempatan ini dilakukan melalui kegiatan bercakapcakap, bercerita dan tanya jawab. Kegiatan ini dilakukan dengan menggunakan media pengajaran bahasa anak khususnya peningkatan kosakata anak. Penggunaan media pengajaran dapat memperjelas penyajian pesan dan informasi belajar anak. Proses belajar bahasa harus melibatkan empat faktor, yakni guru, pengajaran bahasa, metode pengajaran, dan materi pelajaran. ${ }^{2}$ Empat faktor tersebut menjadi bagian penting dari usaha membantu dan memudahkan (facilitate) proses belajar-mengajar. Guru merupakan faktor yang terpenting dalam proses pemudahan belajar ini. Dalam usaha pemudahan ini, guru memerlukan cara-

2 Ahmad Izzan, Metodologi Pembelajaran Bahasa Inggris, (Bandung: Humaniora, 2008), hlm. 23 
cara (metode) tertentu. Jadi guru yang baik umumnya, selalu berusaha untuk menggunakan metode pengajaran yang paling efektif, dan memakai alat-media yang terbaik.

Pengembangan kemampuan berbahasa pada anak-anak bertujuan agar anak mampu mengungkapkan pikiran melalui bahasa yang sederhana secara tepat, mampu berkomunikasi secara efektif dan membangkitkan minat untuk dapat berbahasa dengan baik. Namun dalam kenyataannya tujuan tersebut belum bisa dicapai secara maksimal. Sebagai contoh anak seringkali mendapat kesulitan mengungkapkan pendapatnya ketika pembelajaran berlangsung, sulit mendapatkan jawaban ketika guru bertanya, bahkan untuk berbicara pun anak masih perlu motivasi dan bantuan dari guru.

Berdasarkan hasil pengamatan dilapangan khususnya di SDN Bendan Ngisor Semarang, guru kurang kreatif dalam menyampaikan materi pelajaran, sehingga penyampaian pembelajarannyapun kurang menarik bagi anak, begitu pula dalam pelajaran pengembangan berbahasa khususnya dalam meningkatkan kemampuan kosakata Bahasa Inggris masih terlihat kaku, karena pembelajaran bahasa Inggris dianggap sulit dan tidak menyenangkan. Dalam melakukan suatu kegiatan pembelajaran jarang sekali guru menggunakan metode dan menyediakan media yang menarik bagi anak, sehingga anak terlihat bosan. Sebuah alternatif yang akan dicobakan melalui penelitian tindakan kelas ini adalah penggunaan media pembelajaran. 
Berdasarkan uraian di atas salah satu upaya peningkatan penguasaan kosakata dapat dilakukan melalui pembelajaran dengan media kartu kata dan gambar (flashcard). Oleh karena itu penelitian peningkatan kosakata bahasa Inggris siswa diadakan dengan judul "Upaya Meningkatkan Penguasaan Kosa Kata Siswa Pada Mata Pelajaran Bahasa Inggris Dengan Menggunakan Metode Simulation Game Dengan Media Flashcard di Kelas IV SDN Bendan Ngisor Semarang Tahun Pelajaran 2012/2013".

\section{B. MEDIA FLASHCARD}

Media pembelajaran merupakan wadah dari pesan yang oleh sumber atau penyalurnya ingin diteruskan kepada sasaran atau penerima pesan. ${ }^{3}$ Media adalah alat saluran komunikasi. ${ }^{4}$ Kata media berasal dari bahasa latin, yang merupakan bentuk jamak dari kata medium. Secara harfiah, media berarti perantara, yaitu perantara antara sumber pesan (a source) dengan penerima pesan (a receiver). Menurut Ibrahim, media pembelajaran adalah segala sesuatu yang dapat dipakai untuk memberikan rangsangan sehingga terjadi interaksi belajar mengajar dalam rangka mencapai tujuan instruksional tertentu. ${ }^{5}$ Media pembelajaran adalah segala sesuatu yang dapat menyalurkan pesan, dapat merangsang pikiran, perasaan dan keamanan peserta didik,

3 Nurmaliyah Faridah \& Prabowo Sugeng Listyo, Perencanaan Pembelajaran, (Malang: UIN-Maliki Press, 2010), hlm. 117.

4 Indriana Dina, Ragam Alat Bantu Media Pengajaran, (Jogjakarta: DIVA Press, 2011), hlm.13.

5 Nur Hayati Yusuf, Media Pengajaran, (Surabaya: Dakwah Digital Press, 2005), hlm.6. 
sehingga dapat mendorong terciptanya proses pada dirinya. ${ }^{6}$ Media pembelajaran adalah segala sesuatu yang dapat menyalurkan pesan, dapat merangsang pikiran, perasaan dan keamanan peserta didik, sehingga dapat mendorong terciptanya proses pada dirinya.

Dari beberapa pengertian diatas peneliti menyimpulkan pengertian media adalah sebagai suatu proses yang salah satunya untuk menyampaikan pesan, pembelajaran sangat rentan sekali dengan salah pengertian. Artinya pesan yang disampaikan oleh guru kepada siswa sering kali tidak ditangkap oleh siswa sebagaimana apa yang dimaksud oleh guru. Itulah sebabnya diperlukan sesuatu yang dapat mengurangi kesalah pahaman tersebut. Selain itu, sebagai suatu kegiatan yang dibatasi oleh waktu, pembelajaran juga harus mampu memanfaatkan waktu yang ada atau bahkan mempercepat pencapaian kompetensi yang direncanakan. Untuk hal-hal tersebut itulah kemudian diperlukan media pembelajaran dan salah satu media yang tepat dalam penelitian tindakan kelas ini untuk meningkatkan penguasaan kosa kata pada siswa SDN Bendan Ngisor Semarang di Kelas IV adalah media flashcard.

\section{PENGERTIAN MEDIA PEMBELAJARAN FLASHCARD}

Flash card berasal dari bahasa Inggris, Flash (cepat), Card (kartu). Jadi flash card artinya kartu cepat. Flash card adalah kartu

6 Yunus Nagawa, Metodologi Pembelajaran Agama Islam, (Jakarta: Pustaka Firdaus, 2000), hlm.137. 
kecil yang berisi gambar, teks, atau tanda simbol yang mengingatkan atau menuntun siswa kepada sesuatu yang berhubungan dengan gambar itu. ${ }^{7}$ Flash card adalah kartu ukuran besar, biasanya menggunakan kertas yang agak tebal, kaku dan biasanya ukurannya A4. Flash card memperlihatkan gambar atau tulisan kata-kata, biasanya flash card terdiri atas perangkat yang dikelompokkan menurut jenis atau kelasnya, misalnya kelompok gambar makanan, buah-buahan, gambar seorang yang melaksanakan wudlu, alat transportasi, dan lain-lain. Flashcard adalah media pembelajaran dalam bentuk kartu bergambar yang ukurannya seukuran postcard atau sekitar 25 X $30 \mathrm{~cm} .{ }^{8}$ Flash card adalah media yang tepat untuk membantu siswa/anak mengingat dan mempelajari informasi baru. Kartu ini mudah dibuat dan digunakan. Sebagian besar anak adalah visual learners dan kartu bergambar dengan warna-warna menarik bisa sangat bermanfaat untuk mengajar mereka. Media flash card ini berfungsi untuk mengembangkan daya ingat otak kanan serta melatih kemampuan konsentrasi.

Peneliti menyimpulkan bahwa media pembelajaran flash card adalah media pembelajaran visual yang berbentuk kartu yang berisi gambar atau tulisan yang bisa mengarahkan siswa tentang materi yang dipelajari, sehingga dapat mempercepat pemahaman dan dapat memperkuat ingatan siswa.

${ }^{7}$ Yunus Nagawa, Metodologi Pembelajaran... hlm. 117.

8 Indriana Dina, Ragam Alat Bantu Media Pengajaran, (Jogjakarta: DIVA Press, 2011), hlm.68 


\section{METODE PENELITIAN}

Untuk mendapatkan data yang valid dan lengkap, penelitian menggunakan beberapa metode, sehingga jika salah satu ada kelemahan dapat teratasi oleh metode yang lain. Metode yang digunakan adalah wawancara untuk mendapatkan keteranganketerangan lisan melalui tanya jawab dengan orang yang memberikan keterangan pada peneliti. ${ }^{9}$ Kedua, metode observasi yakni pengamatan yang dilakukan secara sengaja, sistematis mengenai fenomena sosial dengan gejala-gejala psikis untuk kemudian dilakukan pencatatan. ${ }^{10}$ Ketiga, metode dokumentasi dengan mencari data mengenai hal-hal atau variabel yang berupa catatan, transkrip, buku, surat kabar, majalah, prasasti, notulen rapat, lengger, agenda dan sebagainya. ${ }^{11}$ Keempat, metode analisis data pada instrumen lembar observasi dengan menggunakan teknik deskriptif melalui persentase.

Hasil belajar dapat dianalisis dengan cara menghitung ratarata nilai ketuntasan belajar secara klasikal. Adapun rumus yang digunakan untuk menghitung nilai rata-rata :

Nilai rata - rata $=\frac{\text { Jumlah seluruh siswa }}{\mathrm{N} \text { (Jumlah Siswa) }}$

9 Mardalis, Metode Penulisan Suatu Pendekatan Proposal, (Jakarta: Bumi Aksara, 2006), hlm. 64

10 Joko Subagyo, Metode Dalam Teori dan Praktek, (t.t: Rineka Cipta, t. Th), hlm. 63

11 Suharsimi Arikunto, Prosedur Penelitian Suatu Pendekatan Praktis, (Jakarta: Bina Aksara, 1995), hlm. 231. 
Ketuntasan belajar klasikal menggunakan analisis deskriptif persentase dengan perhitungan:

Ketuntasan belajar klasikal $=\frac{\text { Jumlah siswa yang tuntas belajar Jumlah seluruh siswa }}{\text { Jumlah Siswa }} \times 100 \%$

Indikator keberhasilan yang ditetapkan dalam penelitian ini adalah:

a. Untuk perorangan, seorang siswa disebut telah tuntas belajar bila telah mencapai Kriteria Ketuntasan Minimal yang telah ditetapkan yaitu 75 .

b. Tercapainya ketuntasan belajar klasikal yaitu 85\% siswa mendapat nilai 75 atau lebih.

\section{E. HASIL DAN PEMBAHASAN}

Berdasarkan keseluruhan pembahasan serta analisis yang telah dilakukan, maka secara ringkas diperoleh data:

\section{Tabel I. Hasil Tes Pra Siklus}

\begin{tabular}{|l|l|l|l|}
\hline No & $\begin{array}{c}\text { Kriteria } \\
\text { Ketuntasan }\end{array}$ & $\begin{array}{c}\text { Jumlah } \\
\text { Siswa }\end{array}$ & Persentase \\
\hline 1. & Tuntas & 14 & $40 \%$ \\
\hline 2. & Belum tuntas & 21 & $60 \%$ \\
\hline Jumlah & 35 & $100 \%$ \\
\hline
\end{tabular}

$$
\mathrm{KKM}=75
$$


Tabel 2

Rentang Nilai Pra Siklus

\begin{tabular}{|c|c|c|c|c|c|c|c|}
\hline Nilai & 45 & 50 & 55 & 60 & 65 & 75 & 80 \\
\hline Frekuensi & 3 & 7 & 3 & 5 & 3 & 9 & 5 \\
\hline
\end{tabular}

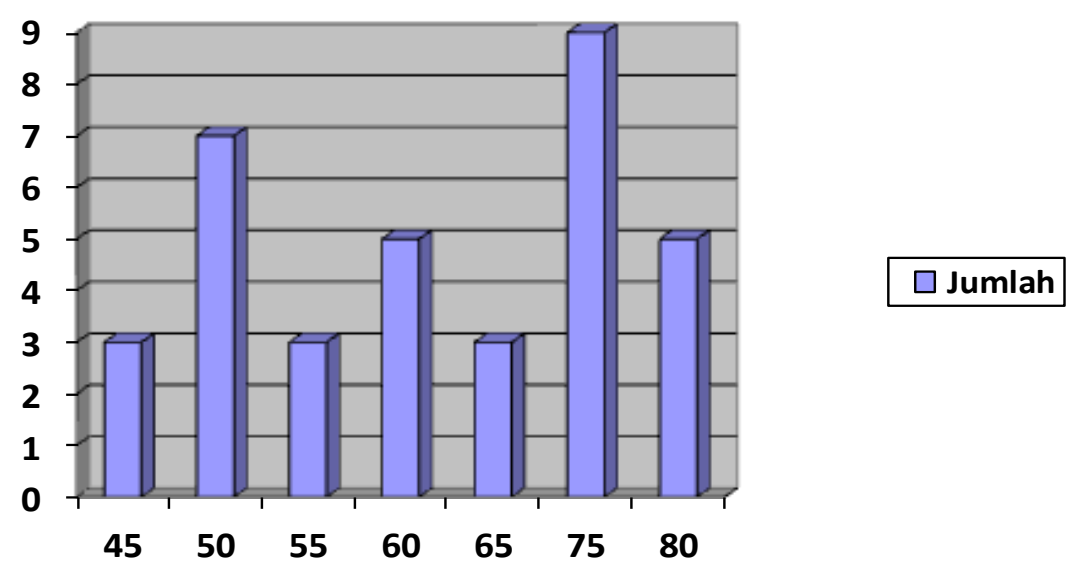

Gambar 1. Grafik Pra Siklus

Pada tahap pra siklus dari 35 siswa terdapat 14 siswa yang belum mencapai kriteria ketuntasan minimal. Secara keseluruhan pada pra siklus belum mencapai ketuntasan minimal yang ditentukan melalui standar nilai yaitu 75. Karena hanya 14 peserta didik (40\%) yang sudah mencapai KKM, sedangkan sisanya 21 peserta didik (60\%) belum mencapai KKM. Dari hasil tes tersebut didapat nilai terendah 45, tertinggi 80 dan rata-rata 63. 
Tabel 3. Ketuntasan Tes Siklus I

\begin{tabular}{|l|l|c|c|}
\hline No & $\begin{array}{c}\text { Kriteria } \\
\text { Ketuntasan }\end{array}$ & Jumlah & Persentase \\
\hline 1. & Tuntas & 23 & $65,7 \%$ \\
\hline 2. & Belum tuntas & 12 & $34,3 \%$ \\
\hline \multicolumn{2}{|l|}{ Jumlah } & 35 & $100 \%$ \\
\hline
\end{tabular}

Batas Tuntas $=75$

Tabel 4. Rentang Nilai Siklus I

\begin{tabular}{|c|c|c|c|c|c|c|c|c|c|c|}
\hline Nilai & 50 & 55 & 60 & 65 & 70 & 75 & 80 & 85 & 90 & Jumlah \\
\hline Frekuensi & 2 & 1 & 3 & 3 & 3 & 13 & 4 & 4 & 2 & 35 \\
\hline
\end{tabular}




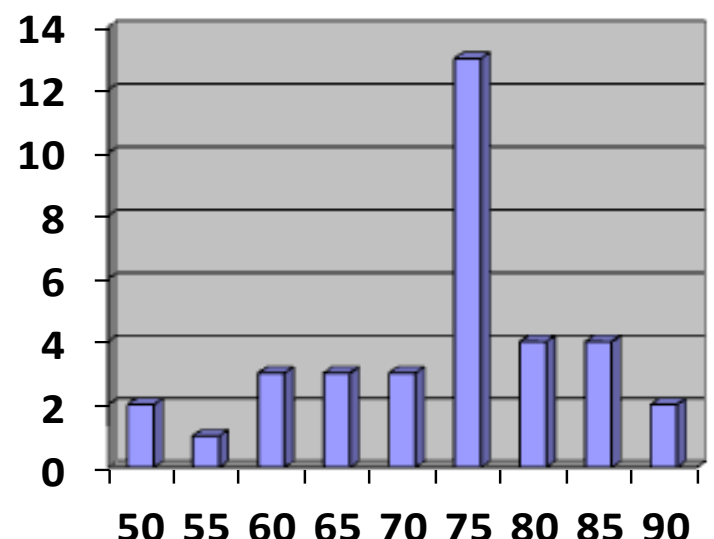

\section{$\square$ Jumlah}

Gambar.2 Grafik Siklus I

Hasil tes menyatakan, 12 siswa atau sebanyak (34\%). Bagi yang telah tuntas sebanyak 23 siswa atau sebanyak (66\%), dengan nilai terendah 50 dan nilai tertinggi 90. Secara keseluruhan keberhasilan pada siklus I cukup baik tetapi masih banyak siswa yang belum mencapai ketuntasan belajar minimal

Tabel 5. Ketuntasan Hasil Tes Siklus II

\begin{tabular}{|l|l|c|c|}
\hline No & $\begin{array}{c}\text { Kriteria } \\
\text { Ketuntasan }\end{array}$ & $\begin{array}{c}\text { Jumlah } \\
\text { Siswa }\end{array}$ & Persentase \\
\hline 1. & Tuntas & 30 & $85,7 \%$ \\
\hline 2. & Belum tuntas & 5 & $14,3 \%$ \\
\hline Jumlah & 35 & $100 \%$ \\
\hline
\end{tabular}

Batas Tuntas $=75$ 
Tabel 6.Rentang Nilai Siklus II

\begin{tabular}{|c|c|c|c|c|c|c|c|c|}
\hline Nilai & 60 & 70 & 75 & 80 & 85 & 90 & 95 & 100 \\
\hline Frekuensi & 1 & 4 & 4 & 3 & 9 & 6 & 3 & 5 \\
\hline
\end{tabular}

Gambar 3. Grafik Siklus II

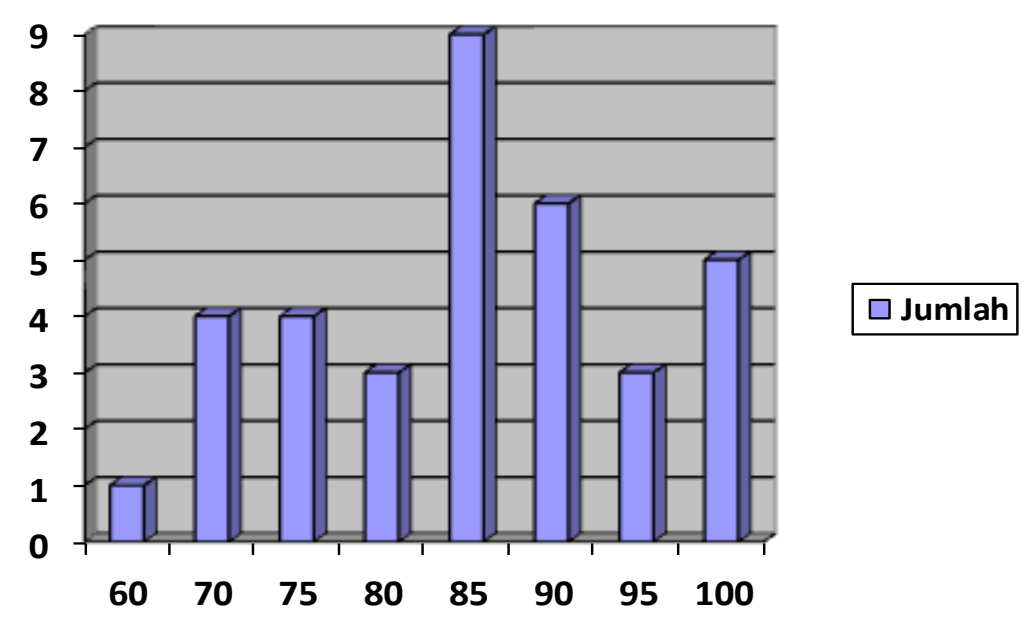

Dari hasil tes di dapat nilai terendah 70, tertinggi 100 dan ratarata 85. Secara keseluruhan keberhasilan pada siklus II ini sudah mencapai ketuntasan minimal sedangkan untuk ketuntasan klasikal juga telah mencapai $86 \%$ yaitu diatas standar yang telah ditentukan yaitu $80 \%$ 
Tabel 7. Perbandingan rata-rata evaluasi pada tahap Pra siklus, siklus I, dan siklus II

\begin{tabular}{|l|l|l|l|}
\hline No & $\begin{array}{l}\text { Pelaksanaan } \\
\text { Siklus }\end{array}$ & Ketuntasan & Prosentase \\
\hline 1 & Pra Siklus & 10 & $40 \%$ \\
\hline 2 & Siklus I & 23 & $66 \%$ \\
\hline 3 & Siklus II & 30 & $86 \%$ \\
\hline
\end{tabular}
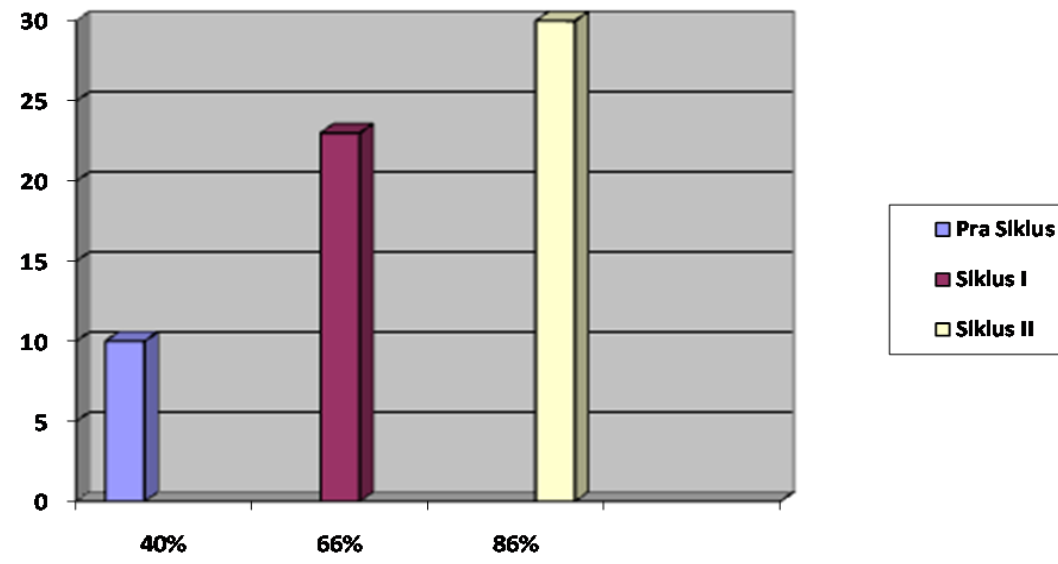

Gambar.4 Grafik Perbandingan Rata-rata Evaluasi Pra Siklus, Siklus I dan Siklus II

Dari hasil penelitian antara pra siklus, siklus I, dan siklus II terjadi peningkatan hasil belajar. Pada tahap pra siklus di dapat 
nilai ketuntasan klasikal:

$\mathrm{P}=\frac{14}{35} \times 100 \%$

$\mathrm{P}=40 \%$

Pada pra siklus tersebut dapat disimpulkan bahwa didapat nilai terendah 45, tertinggi 80 dan rata-rata 63. Secara keseluruhan keberhasilan pada pra siklus belum mencapai ketuntasan minimal yang ditentukan melalui standar nilai yaitu 75. Karena hanya 14 siswa (40\%) yang sudah mencapai KKM, sedangkan sisanya 21 peserta didik (60\%) dari 35 peserta didik kelas IV yang belum mencapai KKM.

Pada pengamatan siklus I dari hasil diperolehan nilai ketuntasan klasikal yaitu dengan rumus:

$\mathrm{P}=\frac{23}{35} \times 100 \%$

$P=66 \%$

Pada siklus ini mengalami peningkatan yaitu hanya 13 peserta didik (34\%), dan yang telah tuntas belajar sebanyak 22 siswa (66\%) dari 35 siswa. Pada pengamatan siklus II dari hasil diperolehan nilai ketuntasan klasikal yaitu dengan rumus:

$$
\begin{aligned}
& \mathrm{P}=\frac{30}{35} \times 100 \% \\
& \mathrm{P}=86 \%
\end{aligned}
$$


Siklus II diperoleh hasil peserta didik telah mencapai ketuntasan belajar sebanyak 30 (86\%), yang belum tuntas hanya 5 (14\%) dari 35 peserta didik kelas IV dengan memperoleh ketuntasan klasikal 86\%.

\section{F. KESIMPULAN}

Dari hasil penelitian dapat disimpulkan bahwa media flashcard dapat meningkatkan penguasaan kosakata pada mata pelajaran Bahasa Inggris. Hal ini dapat dibuktikan dengan hasil evaluasi dengan nilai rata-rata 85 dan hasil ketuntasan klasikal sebanyak $86 \%$. 


\section{DAFTAR PUSTAKA}

Dina, Indriana Ragam Alat Bantu Media Pengajaran, Jogjakarta: DIVA Press, 2011

Faridah, Nurmaliyah \& Listyo, Prabowo Sugeng, Perencanaan Pembelajaran, Malang: UIN-Maliki Press, 2010

Hurlock, Elizabeth B., Psikologi Perkembangan, Jakarta: Erlangga, 1980

Izzan, Ahmad, Metodologi Pembelajaran Bahasa Inggris, Bandung: Humaniora, 2008

Joko Subagyo, Metode Dalam Teori dan Praktek, t.t: Rineka Cipta, t. Th.

Mardalis, Metode Penulisan Suatu Pendekatan Proposal, Jakarta: Bumi Aksara, 2006

Nagawa,Yunus, Metodologi Pembelajaran Agama Islam, Jakarta: Pustaka Firdaus, 2000

Suharsimi Arikunto, Prosedur Penelitian Suatu Pendekatan Praktis, Jakarta: Bina Aksara, 1995

Yusuf, Nur Hayati, Media Pengajaran, Surabaya: Dakwah Digital Press, 2005 